\title{
Cost Effective Method for Toxicity Screening of Pharmaceutical Wastewater Containing Inorganic Salts and Harmful Organic Compounds
}

\author{
Elina STRADE ${ }^{1,2}$, Daina KALNINA ${ }^{1 *}$ \\ ${ }^{1}$ Institute of General Chemical Engineering, Rudolfs Cimdins Riga Biomaterials Innovations and \\ Development Centre, Riga Technical University, Paula Valdena iela 3/7, Riga, LV-1048, Latvia \\ ${ }^{2}$ Laboratory of Industrial Wastewater Treatment Plant, JSC "Grindeks", \\ Krustpils iela 53, Riga, LV-1057, Latvia
}

\begin{abstract}
Pharmaceutical wastewater biological treatment plants are stressed with multi-component wastewater and unexpected variations in wastewater flow, composition and toxicity. To avoid operational problems and reduced wastewater treatment efficiency, accurate monitoring of influent toxicity on activated sludge microorganisms is essential. This paper outlines how to predict highly toxic streams, which should be avoided, using measurements of biochemical oxygen demand (BOD), if they are made in a wide range of initial concentration. The results indicated that wastewater containing multivalent $\mathrm{Al}^{3+}$ cations showed a strong toxic effect on activated sludge biocenosis irrespectively of dilutions, while toxicity of phenol and formaldehyde containing wastewater decreased considerably with increasing dilution. Activated sludge microorganisms were not sensitive to wastewater containing halogenated sodium salts $(\mathrm{NaCl}, \mathrm{NaF})$ and showed high treatment capacity of saline wastewater. Our findings confirm that combined indicators of contamination, such as chemical oxygen demand (COD), alone do not allow evaluating potential toxic influence of wastewater. Obtained results allow identifying key inhibitory substances in pharmaceutical wastewater and evaluating potential impact of new wastewater streams or increased loading on biological treatment system. Proposed method is sensitive and cost effective and has potential for practical implementation in multiproduct pharmaceutical wastewater biological treatment plants.
\end{abstract}

Keywords - Activated sludge; biochemical oxygen demand; pharmaceutical wastewater; toxicity

\begin{tabular}{lll}
\hline Nomenclature & & \\
BOD & Biochemical oxygen demand & $\mathrm{mg} / \mathrm{L}$ \\
COD & Chemical oxygen demand & $\mathrm{mg} / \mathrm{L}$
\end{tabular}

\section{INTRODUCTION}

Biological wastewater treatment systems in industrial facilities often suffer from instability due to shocks of toxic or inhibitory contaminants being released into the wastewater. Pharmaceutical wastewater is highly polluted multi-component mixture of various organic and inorganic constituents, including hardly biodegradable, toxic and bio-persistent xenobiotics and

${ }^{*}$ Corresponding author.

E-mail address: Daina.Kalnina@ rtu.lv 
antimicrobial agents that may inhibit the biological activity of the activated sludge and cause treatment plant process upsets. Activated sludge microorganisms react to the presence of toxicants in wastewater. Responses displayed include reduced rates of respiration, biomass generation, and BOD degradation patterns [1]. These effects of toxicants can cause failure to reach effluent standards, which also increase treatment costs and cause other operational problems, such as reduction of the efficiency of sludge settling and compacting, because of filamentous bulking and deflocculation [1]-[3]. In extreme cases the bacteria are killed by toxic wastewater, and there is a need for cleanout and reseeding of plant, which is a costly and time-consuming operation [2]. Toxic inflow can cause collapse of nitrification process and lead to significantly exceeded total nitrogen concentration in effluent [4]. Wastewater streams from drug manufacturing also contain residues of active pharmaceutical ingredients (API) and their intermediates, which are classified as micropollutant of emerging concern. They are biologically active compounds that can potentially alter physiology and behavior of non-target organism at low doses [5]. API negatively affect the performance of secondary biological processes in wastewater treatment plants (WWTP), cause shifts in the structure of activated sludge bacterial communities and reduce bacterial diversity in the reactors [6], [7]. Depending on manufacturing processes, the composition and biological treatability as well as salinity of pharmaceutical wastewater fluctuate considerably within a short period of time, which make biological treatment of pharmaceutical wastewater even more troublesome [8]-[12].

To avoid toxic shock to activated sludge microorganisms and ensure the compliance of treated wastewater with regulatory requirements, characterization of wastewater by their degree of biodegradation and potential toxicity to the biocenosis of the specific treatment plant is essential. As toxic influent can partially or completely damage treatment for long periods, protective actions and alternative treatment solutions should be provided when increased toxicity is detected [13], [14]. For companies who treat their own wastewater it is especially important to measure the toxicity of the wastewater before a new process comes on-line to predict their impact on treatment process performance. Mainly inhibitory effect of toxic components depends on their concentration; therefore, potential impact of increased pollution load on biological treatment system should be evaluated in cases when production volumes increase.

Numerous bioassays (toxicity tests) are available for toxicity evaluation [13], [15], [16], but only few are directly relevant to activated sludge microorganisms. For example, the commonly used MicrotoxTM and Biotox TM assays are based on marine luminous bacteria Vibrio fischeri that are not representative of activated sludge microbes and does not reflect the status of the microbial community responsible for treatment [1], [7], [13], [17]. Ecotoxicity tests based on the growth inhibition of algae or plants, mortality of crustaceans or fishes and the mobility inhibition of Daphnia magna are suitable to reflect ecological impact of toxic compounds to aquatic environments and, although are sometimes used in the assessment of toxicity of influent water to biological wastewater treatment processes, they are not relevant to WWTP [18]. Furthermore, the use of higher organisms may be ethically undesirable, such test organisms require specialized equipment and operator skills, long acclimatization time, and are labor intensive, expensive and time consuming [19]. For the evaluation of potential toxicity of influents on a wastewater treatment plant, activated sludge microorganisms should be preferred as test species [20], [21]. Many studies on pharmaceutical wastewater treatment plant shows that the microbial population and diversity is vary from one plant to another depending on wastewater characteristics and operating conditions [22]. In some cases, activated sludge from the pharmaceutical industry showed higher resistance against inhibiting toxicants than the sludge from other sources, since biomass is acclimated by the usual presence of toxic compounds in the influent [23]. These aspects 
highlight the importance of the use of site-specific indicator organisms in toxicity monitoring of influent water, to get accurate results.

For the past two decades, biosensor technologies are undergoing improvements and some biosensors are showing good potential to be used as on-line monitoring tools to provide early warning for WWTP operators to avoid toxic shocks to WWTP's [18]. Enzymes, antibodies, microorganisms or DNA could be used as biological sensing element of biosensor in combination with an appropriate transducer (e.g., electrochemical, optical, colorimetric or piezoelectric) [19]. Wastewater treatment plant can be equipped with early warning system that includes a few toxicity measurement points placed at selected locations [4].

Oxygen demand obtained in respirometric assays represents a direct measure of the activity of microorganisms present in aerobic activated sludge. Furthermore, since respiration of the activated sludge is inhibited in the presence of toxicants, it can be used as an efficient tool for the measurement of acute toxicity on microbial population of biological WWTP sludge [16].

The aim of this study was to evaluate the toxic effect of pharmaceutical wastewater streams containing harmful organic substances and inorganic salts on a mixed culture from activated sludge, which was sampled from operating WWTP treating multiproduct pharmaceutical wastewater. Toxicity was assessed by direct observing the effects of toxicants on the BOD degradation activity of the activated sludge microorganisms by exposing test organisms to various doses of the pollutant. Experiments were performed using chemically polluted wastewater streams from JSC "Grindeks" pharmaceutical production facility.

\section{MAterials AND Methods}

\subsection{Preparation of Seeded Dilution Water}

Determination of BOD was done by using the modified standardized method ISO 5815:1989. Required volume of distilled water for preparation of dilution series was filled in a suitable glass container. $1 \mathrm{~mL}$ of each of the salt solutions (Table 1) was added to $1 \mathrm{~L}$ of distilled water. Obtained solution was aerated for $1 \mathrm{~h}$ by using compressor GAST DOA-P504-BN. The dissolved oxygen concentration in dilution water should be at least $8 \mathrm{mg} \mathrm{L}^{-1}$. The water shall not be supersaturated with oxygen, so it must be allowed to stand $1 \mathrm{~h}$ in an opened container before use. Settled activated sludge biomass ( $2 \mathrm{~mL}$ to $1 \mathrm{~L}$ dilution water) from JSC „Grindeks” WWTP was added as seed material (inoculum). The oxygen consumed over 5 days, at $20{ }^{\circ} \mathrm{C}$ of the seeded dilution water, which is the blank value, shall not exceed $1.5 \mathrm{mg} \mathrm{L}^{-1}$ of oxygen.

TABle 1. PREPARATION OF SALTS SOlutions

\begin{tabular}{ll}
\hline Name & Concentration, $\mathrm{mg} \mathrm{L}^{-1}$ water \\
\hline Phosphate buffer solution: & \\
$\mathrm{KH} 2 \mathrm{PO} 4$ & 8500 \\
$\mathrm{~K} 2 \mathrm{HPO} 4$ & 21750 \\
$\mathrm{Na} 2 \mathrm{HPO} 4 \cdot 7 \mathrm{H} 20$ & 33400 \\
$\mathrm{NH} 4 \mathrm{Cl}$ & 1700 \\
$\mathrm{MgSO} 4 \cdot 7 \mathrm{H} 2 \mathrm{O}$ solution & 22500 \\
$\mathrm{CaCl} 2$ solution & 27500 \\
$\mathrm{FeCl3} \cdot 6 \mathrm{H} 2 \mathrm{O}$ solution & 250 \\
Allylthiourea solution & 1000 \\
\hline
\end{tabular}




\subsection{Preparation of Test Solutions (Dilution Series)}

The dilution of the test sample was carried out in a $500 \mathrm{~mL}$ volumetric flask. Set of 7 different dilutions were prepared for each sample. Known volume of the sample to be analysed and $1 \mathrm{~mL}$ of an allylthiourea solution (Table 1) was added in each flask for inhibition of nitrification. Then flasks were filled to the mark with seeded dilution water and mixed gently. Blank sample was prepared in parallel, by using seeded dilution water and allylthiourea solution (Table 1). Organic content of the samples was characterized by chemical oxygen demand (COD) values.

Incubation bottles $(\mathrm{V}=350 \mathrm{~mL})$ were filled with each dilution allowing them to overflow slightly. Initial dissolved oxygen concentration at time zero was measured in each bottle. Then bottles were stoppered and put in the incubator at $20^{\circ} \mathrm{C}$ in darkness for 5 days. After the incubation, dissolved oxygen concentration was measured in each bottle again.

\section{3. $\mathrm{BOD}_{5}$ Calculation}

$\mathrm{BOD}_{5}$ calculation was done by using Eq. (1):

where

$c_{1} \quad$ dissolved oxygen concentration of one of the test solution at time zero, $\mathrm{mg} \mathrm{L}^{-1}$;

$c_{2}$ dissolved oxygen concentration of this same test solution after 5 days, $\mathrm{mg} \mathrm{L}^{-1}$;

$c_{3}$ dissolved oxygen concentration of the blank solution at time zero, $\mathrm{mg} \mathrm{L}^{-1}$;

$c_{4} \quad$ dissolved oxygen concentration of the blank solution after 5 days, $\mathrm{mg} \mathrm{L}^{-1}$;

$V_{\mathrm{e}} \quad$ volume of sample used for the preparation of the test solution concerned, $\mathrm{mL}$;

$V_{\mathrm{t}} \quad$ total volume of this test solution, $\mathrm{mL}$.

\subsection{Apparatus and Equipment}

COD analyses were done by using HACH LANGE cuvette tests LCK 014 and LCK 514. Measurements were done by the spectrophotometer HACH DR 5000. The HACH LANGE thermostat HT 200S was used to heat the samples. Concentration of $\mathrm{Cl}^{-}$and phenols was determined by using HACH LANGE cuvette tests LCK 311 and LCK 349 respectively. Dissolved oxygen concentration in the respirometric assays was measured with dissolved oxygen meter WTW inolab Oxi Level 2. Incubation of samples at $20^{\circ} \mathrm{C}$ was done in thermostat WTW TS 606/2. Analytical grade reagents from Acros Organics were used for preparation of salt solutions.

\subsection{Wastewater and Sludge Sampling}

JSC "Grindeks" is the leading pharmaceutical company in the Baltic States and produces about 25 different kinds of active pharmaceutical ingredients belonging to heart and cardiovascular, CNS and anticancer medication therapeutic groups. The wastewater from "Grindeks" pharmaceutical production facility is treated in a five-stage moving bed biofilm reactor (MBBR) plant, including COD removal, nitrification and denitrification, after which the wastewater is discharged into the municipal sewer system for the final treatment. The composition and biotreatability of wastewaters are variable and highly stressful for microorganisms. Influent COD load varies from 1 to $2.5 \mathrm{t}$ per day and the total nitrogen load is in the range from 0.015 to $0.045 \mathrm{t}$ per day, while the wastewater flow varies from 160 to $360 \mathrm{~m}^{3} \mathrm{~d}^{-1}$. The hydraulic retention time (HRT) of the plant is in the range of 3-6 days and COD removal is $93-94 \%$ in average. Activated 
sludge inoculum for BOD measurements was taken from last MBBR where organic biological degradation takes place.

\section{RESULTS AND DISCUSSION}

Pharmaceutical compounds at JSC "Grindeks" are typically produced in multi stage batch processes leading to the presence of a wide variety of products in wastewaters which are generated in different operations - chemical synthesis, washing or extraction of chemical product, washing of equipment, recovery of solvents. To minimize the fluctuation of pollution load and wastewater flow, wastewater from production sites is collected in the equalization tank and dosed to the MBBR system. As shown in the Fig. 1, regular wastewater is relatively well biodegradable. Considerable toxic effect on activated sludge microorganisms is not detected. Depending on the degree of dilution, BOD varies from 22.4 to $53.2 \%$ of COD (Table 2). The ratio BOD/COD is called Biodegradability index and is commonly used as an indicator for biodegradation capacity [24]. COD values of tested (undiluted) samples are used to calculate the ratio BOD/COD. Low ratio $\mathrm{BOD} / \mathrm{COD}$ indicate the presence either of organic matter that are hard to biodegrade or of toxic substance inhibiting the microbial activities [25].

Fig. 1 and Fig. 2 demonstrate BOD values of chemically polluted pharmaceutical wastewater as a function of dilution factor under two different background conditions. The obtained BOD curves show the response of biocenosis of the biological WWTP to highly organically polluted wastewater streams and presence of inorganic compounds in wastewaters. Dilutions in range from 100-700 were tested, which corresponds to the real amount of wastewater generated per day and their potential dilution in equalization tank of WWTP of "Grindeks".

Toxic and refractory organic compounds are one of major challenges for biological wastewater processes. We used formaldehyde and phenol containing wastewaters as representative contaminants of pharmaceutical wastewaters for our experiments. Phenol and formaldehyde have strong bio-resistance and toxicity to microbes thus limiting the use of biological treatment method [26]. Obtained results show that biodegradability of pharmaceutical wastewater containing such toxic substances depends on concentration of toxicants.

Formaldehyde is highly reactive chemical compound and is widely used in the chemical industry as a raw material and solvent for the production of various products, and as a result it also enters into chemical wastewater. Because of its toxicity [27], formaldehyde is also widely used as a preservative and disinfectant to inhibit the activity of microorganisms; therefore, it is already predictable that its presence may inhibit biological processes in WWTP's [28]. As shown in Fig. 1 biodegradability of formaldehyde containing wastewater is expressly dependent on the degree of dilution of the sample. As formaldehyde concentration increases, it inhibits the biological activity of activated sludge microorganisms, respiration decreases, and biodegradation is disrupted.

Phenol, like formaldehyde, comes into pharmaceutical wastewater of JSC "Grindeks" as a byproduct of chemical synthesis and is considered as very toxic compound to living organisms [29]. Although phenol is reported as toxic and inhibitory substrate, however it is also carbon source for an acclimated biomass [30], [31]. Experimental data show that with increasing initial concentration of phenol in the solution, BOD values decrease noticeably. The shape of BOD curve is similar to that of formaldehyde containing wastewater. Obtained results are consistent with studies by other authors that the phenol is recognized as an inhibitory substrate to activated sludge at relatively low concentrations $\left(100 \mathrm{mg} \mathrm{L}^{-1}\right)$ [32].

As shown in Fig. 1, the BOD results are informative only if measurements are made in a wide range of initial concentration. The biodegradability and toxicity of organically contaminated wastewater is strongly dependent on the dilution. 


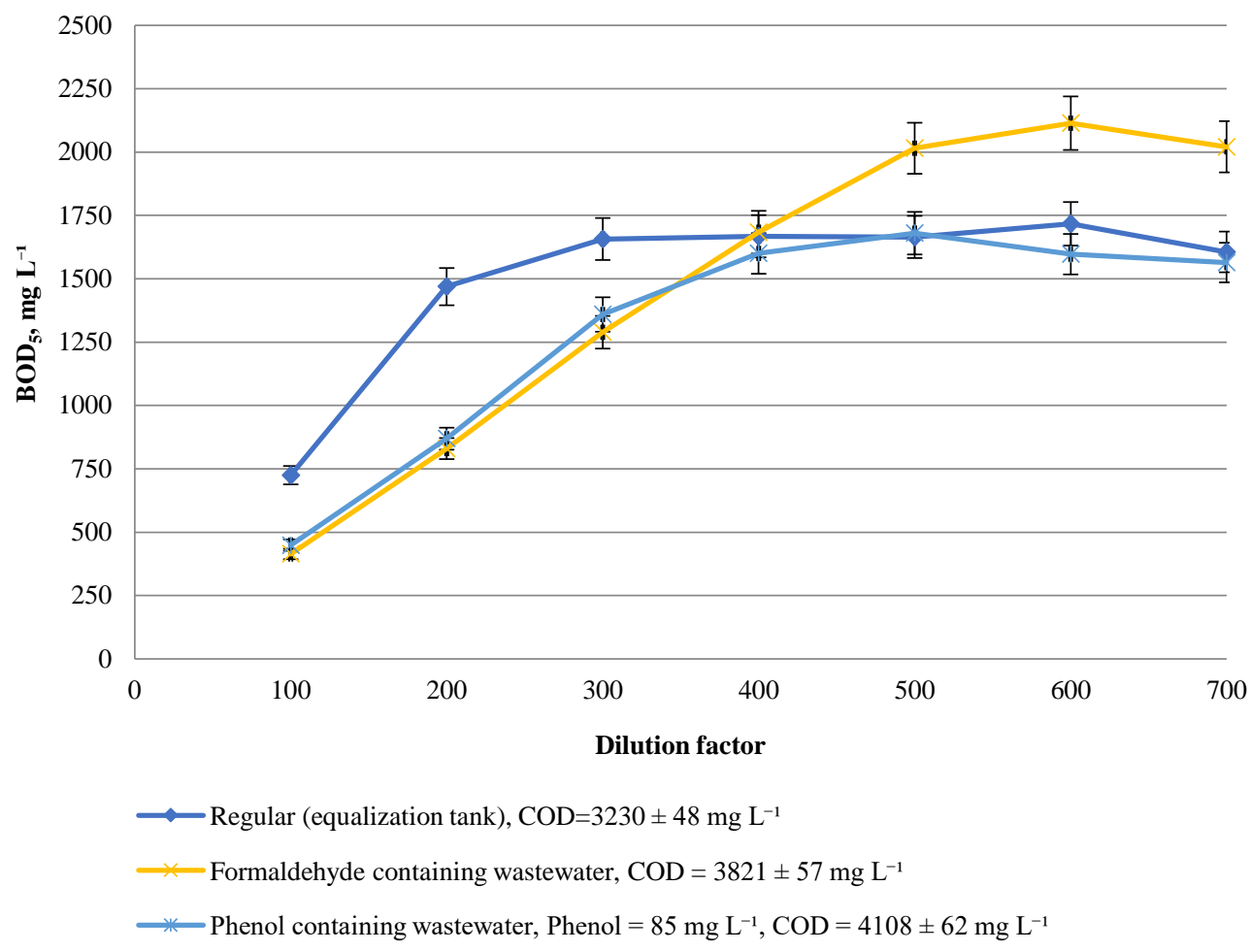

Fig. 1. $\mathrm{BOD}_{5}$ values of pharmaceutical wastewater's streams containing harmful organic compounds depending on dilution factor.

Results show that the biodegradation curves of wastewater containing phenol and formaldehyde reach the plato phase only at dilution factor of 500. Construction of an equalization tank appears to be of extreme importance in order to ensure dilution of toxic wastewater streams and avoid toxic shock to biological treatment system treating pharmaceutical wastewater. The obtained data can be used to estimate amount of specific wastewater that will not affect the stability of the biological treatment process and can be discharged into WWTP. However, it should be considered, that possible synergistic or antagonistic interactions between pollutants are possible [33].

High salinity in wastewaters is another key issue affecting the performance of biological processes. Inorganic salts, like $\mathrm{NaCl}, \mathrm{NaF}, \mathrm{MgSO}_{4}, \mathrm{Na}_{2} \mathrm{CO}_{3}, \mathrm{NH}_{4} \mathrm{Cl}$, are commonly used and are typical pollutants of pharmaceutical wastewater. Pharmaceutical industry generates saline wastewater, rich in both salts and organic matter. The activity of microorganisms usually is affected by high salt concentration $(>2 \% \mathrm{w} / \mathrm{v})$, which can lead to the low COD removal efficiency, decreased nitrification and denitrification rate and bulking of the activated sludge as well as increased turbidity [34], [35], therefore it is important to investigate the impact of inorganic salts on activated sludge. 


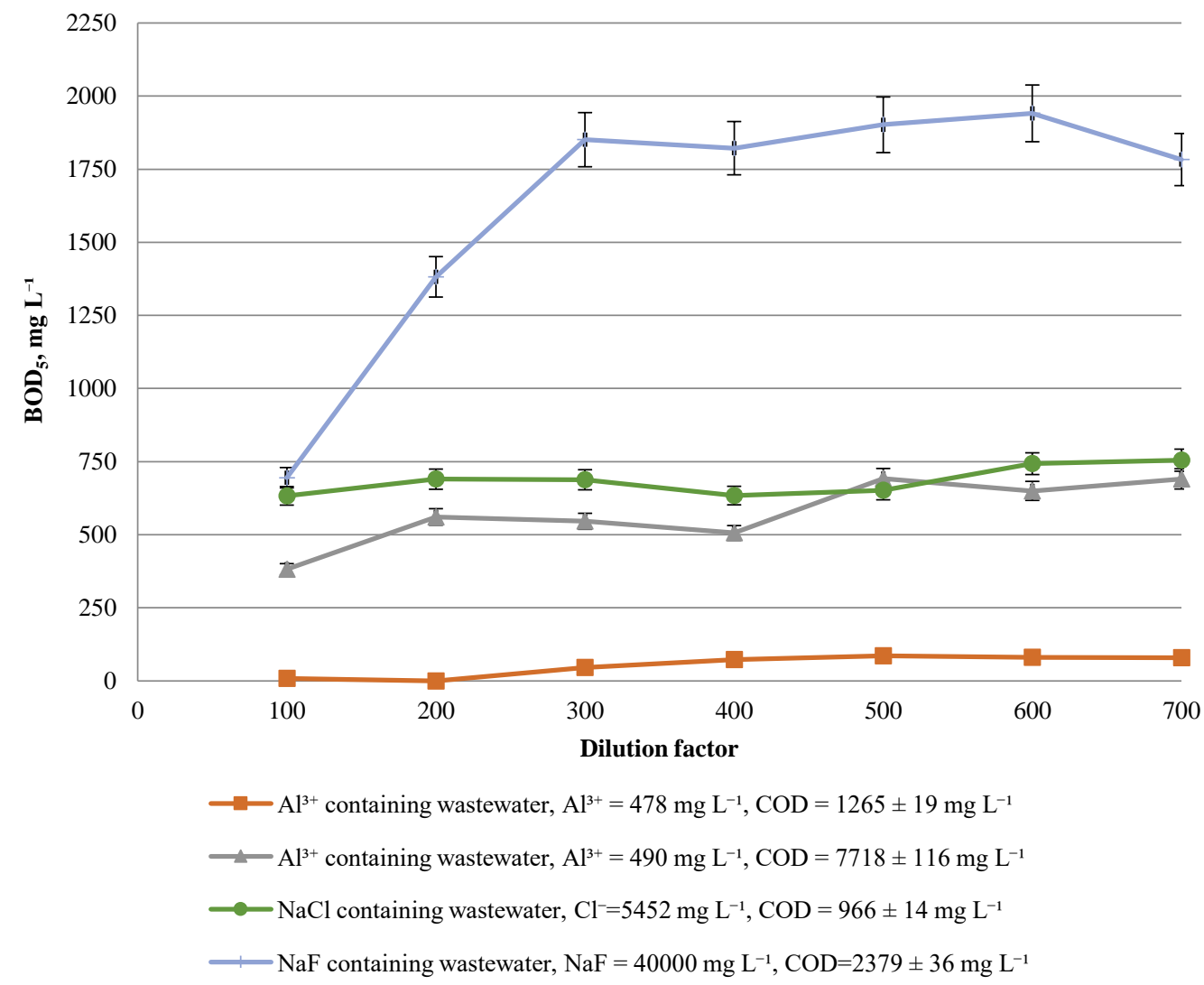

Fig. 2. $\mathrm{BOD}_{5}$ values of pharmaceutical wastewater's streams containing inorganic salts depending on dilution factor.

The salinity inhibition on biological treatment is mainly caused by osmotic pressure, which may lead to plasmolysis of microbial cells and eventual death of microorganisms eventually leading to the failure of biological treatment systems [36], [37]. Major fluctuation of salinity can cause salinity shock, for this reason, high salinity wastewater must be diluted before biological treatment in most cases, which increases operational costs and water consumption [36]. Each microbial species has its optimum growth salinity, and microorganisms will lose their activity beyond the tolerance limit [38]. In many studies halophilic salt-tolerant microorganisms were considered adaptable to treat saline wastewater [34], [37]. Salt-adapted microorganisms are capable of withstanding high salinities and at the same time of degrading the pollutants that are contained in wastewater [35]. As salt removal from saline wastewater by reverse osmosis or ion exchange is expensive, biological treatment of hyper-saline wastewater with halophilic sludge is recommended [35]. 
TABLE 2. RATIO BOD 5 /COD (\%) DEPENDING ON DILUTION FACTOR

\begin{tabular}{|c|c|c|c|c|c|c|c|c|}
\hline \multirow{3}{*}{ Type of wastewater } & \multirow{3}{*}{$\mathrm{COD}, \mathrm{mg} \mathrm{L}^{-1}$} & \multicolumn{7}{|c|}{ Ratio $\mathrm{BOD}_{5} / \mathrm{COD}, \% *$} \\
\hline & & \multicolumn{7}{|c|}{ Dilution factor } \\
\hline & & 100 & 200 & 300 & 400 & 500 & 600 & 700 \\
\hline Regular (equalization tank) & $3230 \pm 48$ & 22.4 & 45.4 & 51.3 & 51.6 & 51.5 & 53.2 & 49.7 \\
\hline $\begin{array}{l}\mathrm{Al}^{3+} \text { containing wastewater, } \\
\mathrm{Al}^{3+}=478 \mathrm{mg} \mathrm{L}^{-1}\end{array}$ & $1265 \pm 19$ & 0.6 & 0.5 & 3.6 & 5.8 & 6.8 & 6.3 & 6.3 \\
\hline $\begin{array}{l}\mathrm{Al}^{3+} \text { containing wastewater, } \\
\mathrm{Al}^{3+}=490 \mathrm{mg} \mathrm{L}^{-1}\end{array}$ & $7718 \pm 116$ & 5.0 & 7.3 & 7.1 & 6.6 & 9.0 & 8.4 & 9.0 \\
\hline $\begin{array}{l}\text { Formaldehyde containing } \\
\text { wastewater }\end{array}$ & $3821 \pm 57$ & 10.8 & 21.7 & 33.7 & 44.1 & 52.7 & 55.3 & 52.9 \\
\hline $\begin{array}{l}\text { Phenol containing wastewater, } \\
\text { Phenol }=85 \mathrm{mg} \mathrm{L}^{-1}\end{array}$ & $4108 \pm 62$ & 10.9 & 21.2 & 33.1 & 38.9 & 40.9 & 38.9 & 38.1 \\
\hline $\begin{array}{l}\mathrm{NaCl} \text { containing wastewater, } \\
\mathrm{Cl}^{-}=5452 \mathrm{mg} \mathrm{L}^{-1}\end{array}$ & $966 \pm 14$ & 65.5 & 71.4 & 71.3 & 65.6 & 67.5 & 76.9 & 78.2 \\
\hline $\begin{array}{l}\mathrm{NaF} \text { containing wastewater, } \\
\mathrm{NaF}=40000 \mathrm{mg} \mathrm{L}^{-1}\end{array}$ & $2379 \pm 36$ & 29.2 & 58.1 & 77.8 & 76.6 & 79.9 & 81.6 & 75.0 \\
\hline
\end{tabular}

Saturated solution of $\mathrm{NaCl}$ is widely used in the pharmaceutical industry to extract the chemical products. Although according to literature data biological treatment is strongly inhibited by salts (mainly $\mathrm{NaCl}$ ) [35], respirometric data show, that $\mathrm{NaCl}$ concentration in influent wastewater of WWTP of JSC "Grindeks" does not reach inhibitory level on activated sludge microorganisms. This can be explained by the fact that concentration of $\mathrm{NaCl}$ in tested wastewater corresponds to the physiological saline and BOD tests were done at high dilution. The results of the respirometry experiment allow concluding that the organic matter of the sample has good biodegradability the ratio of $\mathrm{BOD}_{5} / \mathrm{COD}$ is greater than $65 \%$ and does not essentially changes with dilution (Table 2).

Saturated $\mathrm{NaF}$ aqueous solution in the synthesis of pharmaceutical products forms as a byproduct of the fluorination reaction. Although fluoride is a common contaminant in a variety of industrial wastewaters, available information on the potential toxicity of fluoride to microorganisms located in biological wastewater treatment plants is very limited. The fluoride concentration in untreated industrial wastewater can vary over a large range from 500-2000 $\mathrm{mg} \mathrm{L}^{-1}$ [39]. Experimental data show that NaF inhibit activated sludge microorganisms from pharmaceutical WWTP only at dilution factor 100 . With increasing dilution, the $\mathrm{BOD}_{5} / \mathrm{COD}$ ratio is above $70 \%$, which indicates that activated sludge microorganisms tolerate fluoride at relatively high concentrations. Activated sludge microorganisms of JSC “Grindeks" are exposed to continuously inflow of halogenated salts and are acclimated to increased salt concentration. The obtained results allow concluding that halogenated sodium salts with tested halogenates concentration do not impact removal of organic matter in wastewater.

$\mathrm{AlCl}_{3}$ is used as a catalyst in chemical synthesis, and therefore multivalent $\mathrm{Al}^{3+}$ cations are regularly discharged into pharmaceutical wastewater. Respirometric experiments were performed on samples with different concentrations of organic matter and practically the same content of $\mathrm{Al}^{3+}$ ions in water. As shown in the Fig. 2, $\mathrm{Al}^{3+}$ ion-containing wastewater is highly toxic to active sludge microorganisms and practically non-biodegradable. The ratio of $\mathrm{BOD}_{5} / \mathrm{COD}$ remains low even at high dilution rates of the sample and does not exceed $10 \%$ (Table 2). The obtained results indicate that $\mathrm{Al}^{3+}$ containing wastewater should not be let into biological treatment plants, as this 
can lead to toxic shock to microorganisms and destroy the active sludge biocenosis. The toxicity of both samples is markedly high; it does not change with the COD increase, which confirms toxicity of $\mathrm{Al}^{3+}$ ions. Chemical pre-treatment - for example, precipitation of aluminium with lime milk, $\mathrm{NaOH}$ or $\mathrm{Na}_{2} \mathrm{CO}_{3}$ at $\mathrm{pH} 6.5$ prior to biological treatment is necessary to reduce toxicity [40]. Adsorption of aluminium ions on activated carbon could also be used as effective treatment method [41].

Our findings do not conflict with other scientists and confirm the statement that aluminium has no biological role and is a toxic nonessential metal to microorganisms [42], [43].

Based on the literature survey is already known, that aluminium in its ionic form is very toxic to most aquatic organisms such as seaweeds, crawfish, and fish [43] causing osmoregulatory failure by destructing the plasma and hemolymph ions [44]. Aluminium is toxic to fish in acidic (mainly pH 5-5.5), unbuffered waters starting at a concentration of $0.1 \mathrm{mg} / \mathrm{L} \mathrm{[45],} \mathrm{[46].}$

In experiments were aluminium salts $\left(\mathrm{AlCl}_{3}, \mathrm{Al}_{2}\left(\mathrm{SO}_{4}\right)_{3}\right)$ were using to improve settlement characteristics of the sludge and overcome the bulking problem, it was found that aluminium is toxic to activated sludge rotifer Lecane inermis and affected negatively rotifers population size even at low concentrations (4.8 EC and 0.48 EC) [47].

Considering that even trivial amount of aluminium in water causes numerous health problems including Alzheimer and dialysis encephalopathy [41], precautionary principles should be implemented, to avoid toxic reactions and discharge of $\mathrm{Al}$ ions containing wastewater in the environment

The obtained data confirm that the pharmaceutical effluents are very different in terms of biodegradability and toxicity to microorganisms. For effluents having the same dilution value, the ratio $\mathrm{BOD}_{5} / \mathrm{COD}$ can vary considerably - up to 10 times, indicating the highly complex nature of pharmaceutical wastewater. The magnitude of this effect is shown in Table 2. The described method is very useful to compare different wastewater streams to each other, evaluate their impact on the biocenosis of wastewater treatment plant and to find the optimum treatment solution.

The variations in experimental curves characterize:

1. The ecotoxicological nature of organic matter;

2. The ability of microorganisms present in activated sludge to utilize the pharmaceutical wastewaters;

3. The character of curves gives additional information about impact of dilution factor on biological treatability and toxicity to the activated sludge microorganisms of wastewaters.

Information concerning the BOD values is important information in the process control of the wastewater treatment facilities. It is essential factor not only in a choosing of optimal treatment regime, but also to evaluate the possibility to mix the wastewater streams and optimize treatment process. This method also could be used to predict new production behaviour in wastewater treatment station and determining the safe rate of discharge into the aeration tanks.

\section{Conclusions}

The obtained results confirm that BOD measurements with local biomass can be used as a screening method for assessing and comparing the biodegradability and the toxicity to activated sludge of different types of chemically polluted wastewaters, if set of dilution series is tested. The extensive initial concentration range used in the experiments extends the use of the method and allows determining at which concentration the toxicity of the sample changes. These data could be use as basis for assessing the risks and predict process performance if production is intensified and the concentration of specific pollutants in wastewater increase or new type of wastewater is generated. 
Experiments with phenol and formaldehyde containing wastewater showed that the toxic effect on the activated sludge disappears with increased dilution of the sample, highlighting the extremely import role of equalizing tank in highly polluted pharmaceutical wastewater treatment processes in order to minimize harsh fluctuations and peak loading of toxic contaminants.

$\mathrm{Al}^{3+}$ ions containing wastewater showed the highest toxicity against activated sludge microorganisms, clearly indicating need of pretreatment prior to biological wastewater treatment stage. At the same time the results show that the numerical values of the COD cannot be the only parameter for objective pollution characterization, since wastewater with lower COD can be more toxic to activated sludge biocenosis than wastewater with a higher COD. Halogenated sodium salts in tested concentration ranges did not leave negative impact on removal of organic matter from wastewater.

The proposed toxicity evaluation method is directly relevant to activated sludge wastewater treatment process, gives representative results, and is very informative, cost effective and simple. Because of the duration of the test, method could not be used as real time toxicity monitoring tool but is very suitable for systematic screening of various wastewater streams in multiproduct factories, because it allows identifying source of toxicity and choosing a reasonable treatment strategy.

\section{REFERENCES}

[1] Neumegen R. A., Fernández-Alba A. R., Chisti Y. Toxicities of Trichlosan, Phenol, and Copper Sulfate in Activated Sludge. Environmental Toxicology 2005:20(2):160-164. doi:10.1002/tox.20090

[2] Davies P. S., Murdoch F. The increasing importance of assessing toxicity in determining sludge health and management policy. Measurement and Control 2002:35(8):238-242. doi:10.1177/002029400203500804

[3] Katritzky A. R., et al. Estimating the toxicities of organic chemicals in activated sludge process. Water Research 2010:44(8):2451-2460. doi:10.1016/j.watres.2010.01.009

[4] Jurga A., Gemza N., Janiak K. A concept development of an early warning system for toxic sewage detection. E3S Web of Conferences 2017:17(00036):1-8. doi:10.1051/e3sconf/20171700036

[5] Sanganyado E., Lu Z., Fu Q., Schlenk D., Gan J. Chiral pharmaceuticals: A review on their environmental occurrence and fate processes. Water Research 2017:124:527-542. doi:10.1016/j.watres.2017.08.003

[6] Kraigher B., Kosjek T., Heath E., Kompare B., Mandic-Mulec I. Influence of pharmaceutical residues on the structure of activated sludge bacterial communities in wastewater treatment bioreactors. Water Research 2008:42(17):4578-4588 doi:10.1016/j.watres.2008.08.006

[7] Vasiliadou I. A., Molina R., Martinez F., Melero J. A., Stathopoulou P. M., Tsiamis G. Toxicity assessment of pharmaceutical compounds on mixed culture from activated sludge using respirometric technique: The role of microbial community structure. Science of The Total Environment 2018:630:808-819. doi:10.1016/j.scitotenv.2018.02.095

[8] Rozitis Dz., Strade E. COD reduction ability of microorganisms isolated from highly loaded pharmaceutical wastewater pre-treatment process. Journal of Materials and Environmental Science 2015:6(2):507-512.

[9] Tekin H., et al. Use of Fenton oxidation to improve the biodegradability of a pharmaceutical wastewater. Journal of Hazardous Materials 2006:136(2):258-265. doi:10.1016/i.jhazmat.2005.12.012

[10] Lefebvre O., et al. Biological treatment of pharmaceutical wastewater from the antibiotics industry. Water Science and Technology 2014:69(4):855-861. doi:10.2166/wst.2013.729

[11] Ma K., Qin Z., Zhao Z., Zhao C., Liang S. Toxicity evaluation of wastewater collected at different treatment stages from a pharmaceutical industrial park wastewater treatment plant. Chemosphere 2016:158:163-170. doi:10.1016/j.chemosphere.2016.05.052

[12] Shi X., Yeap T. S., Huang S., Chen J., Ng H. Y. Pretreatment of saline antibiotic wastewater using marine microalga. Bioresource Technology 2018:258:240-246. doi:10.1016/j.biortech.2018.02.110

[13] Ren S. Assessing wastewater toxicity to activated sludge: recent research and developments. Environment International 2004:30(8):1151-1164. doi:10.1016/j.envint.2004.06.003

[14] Sirtori C., et al. Decontamination industrial pharmaceutical wastewater by combining solar photo-Fenton and biological treatment. Water Research 2009:43(3):661-668. doi:10.1016/j.watres.2008.11.013

[15] Cēbere B., Faltiņa E., Zelčāns N., Kalniṇa D. Toxicity tests for ensuring successful industrial wastewater treatment plant operation. Environmental and Climate Technologies 2009:3(3):41-47. doi:10.2478/v10145-009-0005-8 
[16] Oller I., Malato S., Sánchez-Pérez J. A. Combination of Advanced Oxidation Processes and biological treatments for wastewater decontamination - A review. Science of Total Environment 2011:409(20):4141-4166 doi:10.1016/j.scitotenv.2010.08.061

[17] Philp J. C., et al. Whole cell immobilised biosensors for toxicity assessment of a wastewater treatment plant treating phenolics-containing waste. Analytica Chimica Acta 2003:487(1):61-74. doi:10.1016/S0003-2670(03)00358-1

[18] Xiao Y., De Araujo C., Sze C. C., Stuckey D. C. Toxicity measurement in biological wastewater treatment processes: A review. Journal of Hazardous Materials 2015:286:15-29. doi:10.1016/j.jhazmat.2014.12.033

[19] Hassan S. H. A., Van Ginkel S. W., Hussein M. A. M., Abskharon R., Oh S. E. Toxicity assessment using different bioassays and microbial biosensors. Environment International 2016:92-93:106-118. doi:10.1016/j.envint.2016.03.003

[20] Kungolos A. Evaluation of toxic properties of industrial wastewater using on-line respirometry. Journal of Environmental Science and Health. Part A, Toxic/hazardous Substances \& Environmental Engineering 2005:40(4):869-880. doi:10.1081/ESE-200048292

[21] Gutiérrez M., Etxebarria J., de las Fuentes L. Evaluation of wastewater toxicity: comparative study between Microtox ${ }^{\circledR}$ and activated sludge oxygen uptake inhibition. Water Research 2002:36(4):919-924. doi:10.1016/S0043-1354(01)00299-8

[22] Meherdad F., et al. Identification of Bacterial Population of Activated Sludge Process and Their Potentials in Pharmaceutical Effluent Treatment. British Biotechnology Journal 2014:4(3):317-324. doi:10.9734/BBJ/2014/7913

[23] Surerus V., Giordano G., Teixeira L. A. C. Activated sludge inhibition capacity index. Brazilian Journal of Chemical Engineering 2014:31(2):385-392. doi:10.1590/0104-6632.20140312s00002516

[24] Abdalla K. Z., Hammam G. Correlation between Biochemical Oxygen Demand and Chemical Oxygen Demand for Various Wastewater Treatment Plants in Egypt to Obtain the Biodegradability Indices. International Journal of Sciences: Basic and Applied Research 2014:13(1):42-48.

[25] Mangkoedihardjo S. Biodegradability Improvement of Industrial Wastewater Using Hyacinth. Journal of Applied Sciences 2006:6:1409-1414. doi:10.3923/jas.2006.1409.1414

[26] Cui W., Cui Z., Zhang N., Ma Q., Liu L., Zhang X. A new efficient technology for refractory phenol-formaldehyde resin wastewater treatment. RSC Advances 2016:6(23):19078-19088. doi:10.1039/C5RA21502A

[27] Agency for Toxic Substances and Disease Registry (ASTDR). Toxicological profile for Formaldehyde. Atlanta: U.S. Department of Health and Human Services, Public Health Service, 1999.

[28] Eiroa M., Vilar A., Amor L., Kennes C., Veiga M. C. Biodegradation and effect of formaldehyde and phenol on the denitrification process. Water Research 2005:39(2-3):449-455. doi:10.1016/j.watres.2004.09.017

[29] Agency for Toxic Substances and Disease Registry (ASTDR). Toxicological profile for Phenol. Atlanta: U.S. Department of Health and Human Services, Public Health Service, 2008.

[30] Yoong E. T., Lant P. A., Greenfield P. F. In situ respirometry in an SBR treating wastewater with high phenol concentrations. Water Research 2000:34(1):239-245. doi:10.1016/S0043-1354(99)00142-6

[31] Hussain A., Dubey S. K., Kumar V. Kinetic study for aerobic treatment of phenolic wastewater. Water Resources and Industry 2015:11:81-90. doi:10.1016/j.wri.2015.05.002

[32] Pradeep N. V., et al. Biological removal of phenol from wastewaters: a mini review. Applied Water Science 2015:5(2):105-112. doi:10.1007/s13201-014-0176-8

[33] Heys K. A., Shore R. F., Pereira M. G., Jones K. C., Martin F. L. Risk assessment of environmental mixture effects. RSC Advances 2016:6(53):47844-47857. doi:10.1039/C6RA05406D

[34] Kargi F. Enhanced biological treatment of saline wastewater by using halophilic bacteria. Biotechnology Letters 2002:24(19):1569-1572. doi:10.1023/A:1020379421917

[35] Lefebvre O., Moletta R. Treatment of organic pollution in industrial saline wastewater: A literature review. Water Research 2006:40(20):3671-3682. doi:10.1016/j.watres.2006.08.027

[36] Shi X., Lefebvre O., Ng K. K., Ng H.Y. Sequential anaerobic-aerobic treatment of pharmaceutical wastewater with high salinity. Bioresource Technology 2014:153:79-86. doi:10.1016/j.biortech.2013.11.045

[37] Zhang X., Gao J., Zhao F., Zhao Y., Li Z. Characterization of a salt-tolerant bacterium Bacillus sp. from a membrane bioreactor for saline wastewater treatment. Journal of Environmental Sciences 2014:26(6):1369-1374. doi:10.1016/S1001-0742(13)60613-0

[38] Wang R., et al. Effects of inorganic salts on denitrifying granular sludge: The acute toxicity and working mechanisms. Bioresource Technology 2016:204:65-70. doi:10.1016/j.biortech.2015.12.062

[39] Ochoa-Herrera V., et al. Toxicity of fluoride to microorganisms in biological wastewater treatment systems. Water Research 2009:43(13):3177-3186. doi:10.1016/j.watres.2009.04.032

[40] Negrea A., et al. Studies Concerning the Aluminium Ions Removal from Waste Water. Chemical Bulletin of "POLITEHNICA" University of Timişoara 2005:50:148-51.

[41] Pour P. G., Takassi M. A., Hamoule T. Removal of Aluminum from Water and Industrial Waste Water. Oriental Journal of Chemistry 2014:30(3):1365-1369. doi:10.13005/ojc/300356

[42] Olaniran A. O., Balgobind A., Pillay B. Bioavailability of Heavy Metals in Soil: Impact on Microbial Biodegradation of Organic Compounds and Possible Improvement Strategies. International Journal of Molecular Sciences 2013:14(5):10197-10228. doi:10.3390/ijms140510197 
[43] Jaishankar M., Tseten T., Anbalagan N., Mathew B. B., Beeregowda K. N. Toxicity, mechanism and health effects of some heavy metals. Interdisciplinary Toxicology 2014:7(2):60-72. doi:10.2478/intox-2014-0009

[44] Rosseland B. O., Eldhuset T. D., Staurnes M. Environmental effects of aluminium. Environmental Geochemistry and Health 1990:12(1-2):17-27. doi:10.1007/BF01734045

[45] Sparling D. W. Ecotoxicology Essentials: Environmental Contaminants and Their Biological Effects on Animals and Plants. London: Academic Press, 2016.

[46] Comber S. D. W., Gardner M. J., Churchley J. Aluminium speciation: implications of wastewater effluent dosing on river water quality. Chemical Speciation \& Bioavailability 2005:17(3):117-128. doi:10.3184/095422905782774874

[47] Klimek B., et al. The toxicity of aluminium salts to Lecane inermis rotifers: are chemical and biological methods used to overcome activated sludge bulking mutually exclusive? Archives of Environmental Protection 2013:39(3):127-138. doi:10.2478/aep-2013-0024

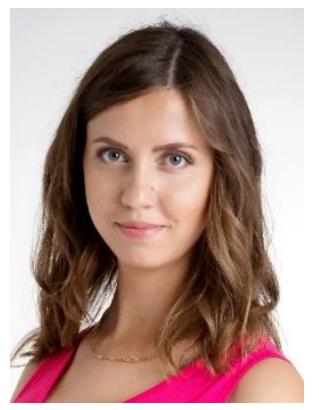

Elina Strade received bachelor degree in chemical engineering at Riga Technical University in 2008. In 2010 She obtained master degree in chemical engineering at Riga Technical University. Since 2017 she is a Ph. D. student at Riga Technical University, Faculty of Materials Science and Applied Chemistry.

Author has background in environmental engineering and ecotoxicology. Since 2010 she is Head of Wastewater Treatment Plant at pharmaceutical company JSC "Grindeks".

ORCID ID: https://orcid.org/0000-0001-6537-3607

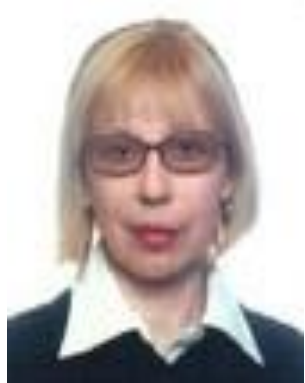

Daina Kalnina received a chemical engineering degree (master's equivalent) from the Riga Technical University. She received the doctor's degree from the University of St.-Petersburg in 1991.

For many years, she was the head of the RTU's Environmental Pollution Laboratory, which was accredited in accordance with ISO 17025 . Currently, her area of research includes understanding the environmental pollution and technologies to destroy it, role of biogenic elements in the water pollution processes and synthesis of Nano and functionalized materials. Dr. Kalnina is Associated Professor and Leading Researcher of the Riga Technical University, faculty of Material Science and Applied Chemistry.

ORCID ID: https://orcid.org/0000-0002-0802-3042 